\title{
Characterization and antibiotic susceptibility of Listeria monocytogenes isolated from poultry and red meat in Morocco
}

\author{
Hayat Ennaji ${ }^{1,2}$ \\ Mohammed Timinouni² \\ My Mustapha Ennaji ${ }^{3}$ \\ Mohammed Hassar' \\ Nozha Cohen' \\ 'Laboratoire de Microbiologie \\ et Hygiène des Aliments et de I \\ 'Environnement, Institut Pasteur \\ du Maroc., Casablanca, Morocco; \\ ${ }^{2}$ Laboratoire de Microbiologie et \\ Biologie Moléculaire, Institut Pasteur \\ du Maroc., Casablanca, Morocco; \\ ${ }^{3}$ Laboratoire de Virologie et Hygiène \\ and Microbiologie., Faculté des \\ Sciences et Techniques - Mohammedia, \\ Université Hassan II, Mohammedia, \\ Morocco
}

Correspondence: Nozha Cohen Laboratoire de Microbiologie et d'Hygiène des Aliments et de L'Environnement, Institut Pasteur. I, Place Louis Pasteur, Casablanca 20100 , Morocco

Tel +212 61869299

$\mathrm{Fax}+21222985063$

Email nozha.cohen@pasteur.ma

\begin{abstract}
This study was carried out on 426 samples of raw meats collected from butcheries and supermarkets in Casablanca, Morocco. The samples were examined for the occurrence of Listeria species. Strains of Listeria monocytogenes were characterized by several biochemical tests and confirmed by polymerase chain reaction (PCR). $\beta$-hemolytic cultures and nonhemolytic isolates were tested for biochemical properties with the Listeria API test. Among the 43 Listeria species isolates; we identified 10 strains for L. monocytogenes (23.3\%), 31 strains for L. innocua (72.1\%) and 2 strains for L. welshimeri (4.6\%). Strains of L. monocytogenes were separated by multiplex PCR; two serogroups IIb and IVb were thus differentiated. Antibiotic susceptibility of L. monocytogenes to 21 antibiotics was determined by the disk diffusion method. All isolates were susceptible to a wide range of the tested antibiotics with the exception of nalidixic acid, colistine and cephalosporins second and third generation for which they were all resistant.
\end{abstract}

Keywords: antibiotic susceptibility, Listeria monocytogenes, meat, PCR

\section{Introduction}

Listeria monocytogenes has long been acknowledged as a significant human and animal pathogen (Schuchat et al 1991; Nightingale et al 2004) and it is often implicated as sources of human listeriosis cases and outbreaks (Aureli et al 2000; De Valk et al 2001). However, sporadic listeriosis remains the most frequent manifestation of the illness (Gilot et al 1996).

The following individuals are at great risk for listeriosis: pregnant women (and their unborn children), new-born, immunocompromised persons (Walter 2000), and the elderly. This infection is regularly reported in Europe and North America, but in Africa and other developing countries (where the food industry is not very developed) only a few sporadic cases have been reported (Boukadidda et al 1994). In Morocco, the incidence of human listeriosis is rare (Benomar et al 2000).

L. monocytogenes often lives in the cold and moist environment found in refrigerators and it is present in all categories of food (Farber and Peterkin 1991; Azevedo et al 2005). Meat, poultry, and meat products have frequently been shown to be contaminated with this pathogenic bacterium (Lawrence and Gilmour 1994; Jay 1996). A number of antibiotics have been suggested for the treatment of L. monocytogenes. Unfortunately, failures have been reported for all therapeutic programs because there is no consensus among various authors as to which antibiotic regimen is the most effective (McLauchlin et al 1991). The mains goals of our work were: i) to detect L. monocytogenes by conventional method and application of a chromogenic medium for the rapid confirmation ii), to confirm and to serotype the strains isolated by polymerase chain reaction (PCR) and multiplex PCR, respectively, iii) and to determine in vitro the activity of various antibiotics against strains of L. monocytogenes isolated from red meat and poultry. 


\section{Materials and methods}

\section{Sample collecting}

A total of 426 samples: (a) raw meat $(n=112)$, (b) meat product $(n=240)$, and $(c)$ poultry $(n=74)$ were collected from butcheries and supermarkets in Casablanca, Morocco. The samples were transported in iceboxes to our laboratory and analyzed immediately upon arrival using the ISO 11290-1 method.

\section{Bacteriological analysis}

Twenty-five grams of each sample were weighed into sterile stomacher bags, diluted with $225 \mathrm{ml}$ of Listeria pre-enrichment Frazer broth (Biokar Diagnostics, BK115HA) homogenized and incubated at $30{ }^{\circ} \mathrm{C}$ for $24 \mathrm{~h}$. A $1 \mathrm{ml}$ portion from this pre-enrichment culture was transferred to $9 \mathrm{ml}$ enrichment broth (Complete Fraser broth, BIO-RAD), and incubated at $37^{\circ} \mathrm{C}$ for $24 \mathrm{~h}$. A loopful of the enrichment culture was streaked onto Palcam, Oxford (AES Laboratory) and RAPID'L. mono (BIO-RAD, France). Plates were incubated at $37^{\circ} \mathrm{C}$ for $24 \mathrm{~h}$ to $48 \mathrm{~h}$. A great advantage of the chromogenic agar, RAPID'L. mono, that it allows for the differentiation $L$.monocytogenes from other $L$. spp. by a simple color change reaction even after $24 \mathrm{~h}$; colonies appear blue. For identification of L. monocytogenes suspect colonies selected from Oxford, Palcam, and RAPID'L. mono agars were streaked on trypticase soya agar plate with $0.6 \%$ yeast extract (TSAYE; Biokar Diagnostics) and tested for Gram coloration, motility, oxydase, CAMP test, and hemolysis test. Typical colonies were characterized biochemically by the Listeria API commercial kit (Biomerieux, Mercy l'Etoile, France).

\section{Molecular analysis}

Total genomic DNA and PCR amplifications were used as described previously (Holoko et al 2002). For $L$. monocytogenes-specific identification, two primers pairs derived from the L. monocytogenes gene: hly1: 5'-CGGAGGTTCCGCAAAAGATG-3' and hly2: 5'- CCTCCAGAGTGATCGATGTT-3' were used. PCRs were carried out in a thermocycler (GeneAmp PCR system 2700, Applied Biosystems) in a $50 \mu \mathrm{l}$ reaction volume containing: $5 \mu \mathrm{l}$ target DNA, $5 \mu \mathrm{L} 10 \times \mathrm{Tp}$ PCR, $200 \mu \mathrm{M}$ dNTP, $1.5 \mathrm{mM} \mathrm{MgCl}_{2} ; 0.4 \mu \mathrm{M}$ of each primer, and 1 Unite of Taq DNA polymerase.

Amplification started with an initial denaturation step at $94{ }^{\circ} \mathrm{C}$ for $5 \mathrm{~min}$, followed by 30 cycles $\left(94^{\circ} \mathrm{C}\right.$ for $1 \mathrm{~min}, 56^{\circ} \mathrm{C}$ for $45 \mathrm{~s}$, and $72^{\circ} \mathrm{C}$ for $45 \mathrm{~s}$ ). Final extension was performed at $72{ }^{\circ} \mathrm{C}$ for $10 \mathrm{~min}$. The PCR products were separated in a $1.2 \%$ agarose gel and stained with ethidium bromide at $0.5 \mu \mathrm{g} / \mathrm{ml}$.

\section{Serotype identification by multiplex PCR}

Serogroups and serovars determinations were performed by multiplex PCR, according to the method described by Doumith and colleagues (2004). These analyses were practiced in the Centre National de Référence des Listeria, Institut Pasteur, Paris.

\section{Antibiotics susceptibility}

Fresh bacterial colonies of $L$. monocytogenes isolates were separately grown at $37^{\circ} \mathrm{C}$ in brain heart infusion broth (BHI) (Merk V4324393-947) for 24 hours and each inoculum was applied on Muller Hinton (MH) agar (BIO-RAD 2M2121). Antibiotic susceptibility was determined by the disk diffusion method. Standard discs were applied using a disc dispenser and the plates were incubated at $37^{\circ} \mathrm{C}$ for $24 \mathrm{~h}$ to $48 \mathrm{~h}$. Then the size of inhibition zone was determined as previously described (Soussy 2005). The Antibiotics tested were selected considering i: the most frequently used in treatment, of farm animals (Johnston 1998). ii: those used to prevent and control infectious diseases in poultry production (Abiola et al 2005). iii: the most important drugs used for the treatment of human infections (Wiggins et al 1978; Winslow and Pankey 1982).

\section{Results \\ Occurrence of $L$. monocytogenes \\ in meats}

Out of 426 samples examined, $43(10 \%)$ were found to be contaminated with $L$. spp. Table 1 presents the types, numbers, and source of the samples analyzed in this study. Among the 43 strains of $L$. species isolates, 10 strains for L. monocytogenes (23\%), 31 strains for L. innocua $(72.1 \%$ ), and 2 strains for $L$. welshimeri (4.6\%) were identified.

\section{Confirmation by PCR}

To confirm the identification of the ten strains characterized by biochemical tests, we have done PCR analyses. We used two primers derived from the virulence associated gene hly specifically those that amplifying the $234 \mathrm{bp}$ region of the listeriolysin O gene. PCR amplification gives all amplicons with same molecular size as shown in Figure 1.

\section{Serotyping}

Analysis of serogroups and serovars distribution showed that L. monocytogenes was represented by two serogroups. The first (IIb) comprised strains of serovars $1 / 2 b, 3 b$, and 7 and the second (IVb) comprised strains of serovars $4 \mathrm{~b}, 4 \mathrm{~d}$, and 4e. The results are shown in Table 2. 
Table I Occurrence of Listeria monocytogenes in red meat and poultry

\begin{tabular}{|c|c|c|c|c|c|}
\hline Type of meat & Nb of samples & L. spp. & L. $\mathrm{m}$. & L. in. & L.w. \\
\hline \multicolumn{6}{|c|}{ Raw meats and meats products } \\
\hline Meats & 112 & $5(4.5 \%)$ & I (0.9\%) & $4(3.5 \%)$ & - \\
\hline Ground meat and sausages & 240 & $23(9.6 \%)$ & $8(3.3 \%)$ & $15(6.2 \%)$ & - \\
\hline Raw poultry & 74 & $15(20.3 \%)$ & I (I.3\%) & $12(16.2 \%)$ & $2(2.7 \%)$ \\
\hline Total & 426 & $43(10.1 \%)$ & $10(2.4 \%)$ & 31 (7.3\%) & $2(0.5 \%)$ \\
\hline
\end{tabular}

\section{Antibiotics susceptibility}

Table 3 summarizes activities of the 21 antibiotics tested against the 10 strains of $L$. monocytogenes isolated from meat and poultry. In general, all isolates are susceptible to a wide range of antibiotics especially for amoxicillin, ticarcillin, gentamicin, tobramycin, amikacin, chloramphenicol, penicillin, and ampicillin. These strains showed different resistance levels of certain antibiotics and were completely resistant to nalidixic acid, colistine, and cephalosprins second and third generations.

\section{Discussion}

In our study the incidence of $L$. monocytogenes was $2.4 \%$ and the rate of contamination in ground meat was $3.3 \%$. Compared to that published by other authors, nearly the same incidences were found in raw minced meat $4.7 \%$ (Yucel et al 2005 ) and moderate incidences $10.6 \%$ have been reported in raw sausages (Cordano and Rocourt 2001). On the contrary, in Tunis the presence of $L$. monocytogenes was lower; out of a total of ground meat samples analyzed only one strain has been contaminated (Ettriqui et al 1995). In the similar study done

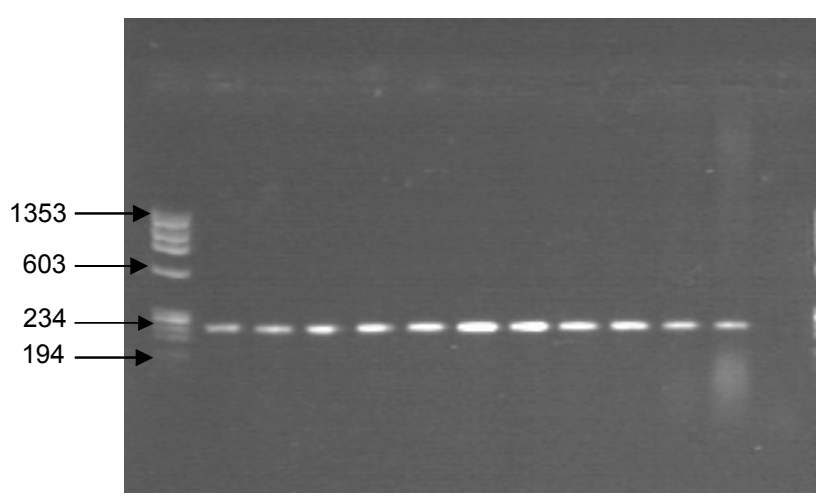

Figure I Identification by PCR of Listeria monocytogenes.

Notes: Lane: I, molecular size marker $\phi \times 174$ diggers by Hae III; Lanes: 2-II, Listeria monocytogenes samples; Lane: I2, reference strain of Listeria monocytogenes (positive control); Lane: I3, negative control. in Morocco, the prevalence of $L$. monocytogenes was $16.4 \%$ in ground bovine meat, and 32\% in raw bovine sausages (Kriem et al 1998). This difference regarding the occurrence between our results realized in Casablanca and those effected in Rabat, Morocco, can be explained by the fact that this study was carried out after the inauguration of the new slaughterhouse installed in Casablanca, on the level of which; legislatives texts governing the inspection of the meats and hygiene have been applied. It relates a whole of a very rigorous control at each key point of the meat production. For the raw meat; from all the samples analysed (112), L. monocytogenes was found in only 1 sample $(0.9 \%)$. According to other studies, the incidence was variable; Yucel and colleagues (2005) and Hilbert and colleagues (2004) detected this organism in 5.2\% and $12 \%$ in beef, respectively.

In Morocco, white meat is an important source of protein. In 2004, the population of Casablanca alone consumed 338,000 tons. Two kinds of poultry slaughtering are used in Morocco. One is an automated poultry slaughtering process established recently, whereby automated systems are used for scalding, plucking, eviscerating, rinsing, and packaging carcasses. Carcasses are then stored at $4{ }^{\circ} \mathrm{C}$ before sale to supermarkets. The second is traditional slaughtering which is commonly practiced in shops under poor hygienic conditions. More than $90 \%$ of poultry slaughtering in Morocco is done by traditional procedures (Cohen et al 2007). For this reason, we have also examined poultry for the occurrence of L. monocytogenes and the incidence rate was (1.3\%). Other data on the prevalence of this bacterium have been reported by others authors in different countries: $11.5 \%$ (Yucel et al 2005 ) and $26 \%$ (Hilbert et al 2004) in chicken meat, and $32 \%$ in poultry meat (Capita et al 2001).

Concerning the antibiotic susceptibility, for gentamicin, all our isolates were susceptible to this antibiotic; our data are similar to those of Aureli and colleagues (2003). Likewise, both penicillin and ampicillin showed good activity against L. monocytogenes; these results are in agreement with those reported previously by Wong and colleagues (1990) who found $98.3 \%$ and $99.4 \%$ of susceptibility, respectively. 
Table 2 Origin of isolates strains and identification of serogroups with multiplex PCR

\begin{tabular}{|c|c|c|c|c|c|c|c|}
\hline \multirow[t]{2}{*}{$N^{\circ}$ of strains } & \multirow[t]{2}{*}{ Origin } & \multicolumn{6}{|c|}{ Multiplex PCR fragment amplification } \\
\hline & & prs & Lmol I I 8 & ImoO737 & ORF2IIO & ORF28I9 & PCR Group \\
\hline I & Sausages & + & - & - & - & + & Ilb \\
\hline 2 & Sausages & + & - & - & + & + & $\mathrm{IVb}$ \\
\hline 3 & Sausages & + & - & - & - & + & Ilb \\
\hline 4 & Meats & + & - & - & - & + & Ilb \\
\hline 5 & Sausages & + & - & - & - & + & Ilb \\
\hline 6 & Ground meat & + & - & - & - & + & Ilb \\
\hline 7 & Sausages & + & - & - & - & + & Ilb \\
\hline 8 & Ground meat & + & - & - & + & + & $\mathrm{IVb}$ \\
\hline 9 & Ground meat & + & - & - & - & + & Ilb \\
\hline 10 & Poultry & + & - & - & - & + & Ilb \\
\hline
\end{tabular}

Abbreviation: $\mathrm{PCR}$, polymerase chain reaction.

The isolates were all susceptible to chloramphenicol, similarly, Yucel and colleagues (2005) indicated that L. monocytogenes isolated from meat products were highly sensitive with a percentage of (100\%). While Aureli and colleagues (2003), showed in their study that the various strains seem to be moderately susceptible (49.1\%) in poultry and totally $(100 \%)$ susceptible in meat. Of the other antibiotics, trimethoprim and trimethoprim in combination with sulfamethoxazole, except for one strain (meat) was resistant to both antimicrobial agents. In previous other findings, Yucel and colleagues (2005) indicated that the percentage of resistant strains of L. monocytogenes in meats was $66 \%$.

Table 3 Activities of antimicrobial agents tested against the strains of Listeria monocytogenes isolated from meat and poultry

\begin{tabular}{|c|c|c|c|c|}
\hline \multirow[t]{2}{*}{ Antimicrobial agent } & \multirow[t]{2}{*}{$\mu \mathrm{g} / \mathrm{disc}$} & \multicolumn{3}{|c|}{ Nb that were susceptible } \\
\hline & & Resistant & Intermediate & Susceptible \\
\hline Amoxicillin (AMX) & 25 & - & - & 10 \\
\hline Ticarcillin (Tic) & 25 & - & - & 10 \\
\hline Cephalotin (CF) & 30 & 01 & - & 09 \\
\hline Cefoxitin (FOX) & 30 & 10 & - & - \\
\hline Cefotaxime (CTX) & 30 & 10 & - & - \\
\hline Ceftazidime (CAZ) & 30 & 10 & - & - \\
\hline Cefazolin (CZ) & 30 & 01 & 01 & 08 \\
\hline Amoxicillin + Clavulanic. Ac (AMC) & $20 / 10$ & - & - & 10 \\
\hline Cefixim (CFM) & 30 & 10 & - & - \\
\hline Gentamicin (GM) & 500 & - & - & 10 \\
\hline Tobramycin (TOB) & 10 & - & - & 10 \\
\hline Amikacin (AN) & 30 & - & - & 10 \\
\hline Trimethoprim (TMP) & 5 & 01 & - & 09 \\
\hline Trimethoprim + Sulfamethoxaxol (SXT) & $1,25 / 23,75$ & 01 & - & 09 \\
\hline Nalidic acid (NA) & 30 & 10 & - & - \\
\hline Colistin (CS) & IOUI & 10 & - & - \\
\hline Neomycin $(\mathrm{N})$ & $30 U \mathrm{I}$ & - & - & 10 \\
\hline Teicoplanin (TEC) & 30 & - & - & 10 \\
\hline Chloramphenicol (C) & 30 & - & - & 10 \\
\hline Penicillin (G) & IOUI & - & - & 10 \\
\hline Ampicillin (AMP) & 10 & - & - & 10 \\
\hline
\end{tabular}


Finally, for the activity of the first generation cephalosporins tested, only one strain (meat) was resistant to cephalotin and cefazolin and one other strain had showed moderate susceptibility to cefazolin. Comparing to others studies realized in various foods (including meats), Wong and colleagues (1990) indicated highly susceptibility to cephalotin (99.4\%). Similarly, Abiun and colleagues (1994) and Navratilova and colleagues (2004) showed that cephalotin displayed good activity. For the second and third generation cephalosporins, we have found resistance to cefotaxime, cefoxitin, cefixim, and ceftazidime. Because of the poor activity or complete resistance of the second and third generation cephalosporins against L. monocytogenes, Cormican and Jones (1995) confirmed that recent cephalosporins should not be used clinically for treating listeriosis.

In conclusion, in this study we have demonstrated that almost all strains of $L$. monocytogenes were susceptible to a wide range of antibiotics effective against Grampositive bacteria, belonging to amino-glycosides group and glycopeptides and some strains among the isolates were resistant to one or more antimicrobial agent. Therefore veterinarians should be able to control the use of antimicrobial drugs in veterinary practice. On the other hand, the survey of this virulent bacterium in meat appears to be critically important from the viewpoint public health. Consistent with other countries, Morocco is experiencing newer consumer trends in the culinary traditions with an obvious tendency to adopt international practice of consuming processed foods, some of which are uncooked or undercooked. Such a tendency combined with incidence of L. monocytogenes contamination reported in meat, thereby increasing the risk of listeriosis for consumers (Cohen et al 2006). Where a suspect sample of poultry will be well cooked before consumption, the risks to the consumer are considered minimal. This is probably the reason why poultry and poultry products are rarely associated with listeriosis (Van Schothorst 1994). Results obtained in this study provide evidence that may be used by the Moroccan government to adopt regulations enforcing the application of the hazard analysis critical control points (HACCP) system as a means to identify and control the hazards in foods and especially in meat products. Furthermore, these results may promote the acceptance of programs such as HACCP by the meat industry in an attempt to provide safer and more wholesome products.

\section{Acknowledgments}

The authors are grateful to Dr Alban Le Monnier and Dr Alexandre LeClercq from Centre National de Référence des Listeria, Institut Pasteur Paris for their collaboration of the molecular serotyping. We also would like to thank the Casablanca authorities for their help.

\section{References}

Abiola FA, Diop MM, Teko-Agbo A, et al. 2005. Antimicrobial agents residues in liver and gizzard of broilers in the areas of Dakar and Thiès (Sénégal). Rev Med Vet, 156:264-8.

Abuin CMF, Fernandez EJQ, Sampayo CF, et al. 1994. Susceptibilities of Listeria species isolated from food to nine antimicrobial agents. Antimicrob Agents Chemother, 38:1655-7.

Aureli P, Fiorucci GC, Caroli D, et al. 2000. An outbreak of febrile gastroenteritis associated with corn contaminated by Listeria monocytogenes. N Engl J Med, 342:1236-41.

Aureli P, Ferrini AM, Mannoni V, et al. 2003. Susceptibility of Listeria monocytogenes isolated from food in Italy to antibiotics. Int $J$ Food Microbiol, 83:325-30.

Azevedo I, Regalo M, Mena C, et al. 2005. Incidence of Listeria spp. in domestic refrigerators in Portugal. Food Control, 16:121-4.

Benomar S, Nejjari N, Lahbabi MS. 2000. Listériose néonatale: une infection exceptionnelle au Maroc. Arch Pediatr, 7:428.

Boukadidda J, Sboui H, Monastiri H, et al. 1994. La listériose humaine en Tunisie: deux nouveaux cas chez le nouveau- né. Med Mal Infect, 24:117-18.

Capita R, Alonso-Calleja C, Moreno B, et al. 2001. Occurrence of Listeria species in retail poultry meat and comparison of a cultural/immunoassay for their detection. Int J Food Microbiol, 65:75-82.

Cohen N, Ennaji H, Hassar M, et al. 2006. The bacterial quality of red meat and offal in Casablanca (Morocco). Mol Nutr Food Res, 50:467-590.

Cohen N, Ennaji H, Bouchrif B, et al. 2007. Comparative study of microbiological quality of raw poultry meat at various seasons and different slaughtering process in Casablanca (Morocco). J Appl Poultry Res, 16:502-8.

Cordano AM, Rocourt J. 2001.Occurrence of Listeria monocytogenes in food in Chile. Int J Food Microbiol, 70:175-8.

Cormican MG, Jones RN. 1995. Antimicrobial activity of cefotaxime tested against infrequently isolated pathogenic species (Unusual Pathogens). Diagn Microbiol Infect Dis, 22:43-8.

De Valk H, Vaillant V, Jacquet C, et al. 2001. Two consecutive nationwide outbreaks of listeriosis in France, October 1999-February. Am J Epidemiol, 154:944-50.

Doumith M, Buchrieser C, Glaser P, et al. 2004. Differentiation of the major Listeria monocytogenes serovars by Multiplex PCR. J Clin Microbiol, 42:3819-22.

Etttriqui A, Dhaou MA, Fliss I, et al. 1995. Research of Listeria monocytogenes in meat products in region of Tunis. MHA, 7:8-13.

Farber JM, Peterkin PI. 1991. Listeria monocytogenes, a food-borne pathogen. Microbiol Rev, 55:476-511.

Gilot P, Genicot A, André P. 1996. Serotype and esterase typing for analysis of Listeria monocytogenes populations recovered from foodstuffs and from human patients with listeriosis in Belgium. J Clin Microbiol, 34:1007-10.

Hilbert F, Mayrhofer S, Paulsen P, et al. 2004. Antimicrobial resistance profile of five major food-borne pathogens isolated from beef, pork and poultry. Int J Food Microbiol, 97:23-9.

Holoko I, Urbanova J, Kantikova M, et al. 2002. PCR Detection of Listeria monocytogenes in milk products and differentiation of suspect isolates. Acta Vet Brno, 71:125-31.

Jay JM. 1996. Prevalence of Listeria spp. in meat and poultry products. Food Control, 7:209-14.

Johnston AM.1998. Use of antimicrobial drugs in veterinary practice. Br Med J, 317:665-7.

Kriem MR, EL-Marrakchi A, Hammama A. 1998. Prevalence of Listeria spp. on a variety of meat products in Morocco. Microbiol Aliment Nutr, 16:179-87. 
Lawrence LM, Gilmour A. 1994. Incidence of Listeria spp. and Listeria monocytogenes in a poultry processing environment and in poultry products and their rapid confirmation by multiplex PCR. Appl Environ Microbiol, 60:4600-4.

McLauchlin J, Audurier A, Taylor AG. 1991. Treatment failure and recurrent human listeriosis. J Antimicrob Chemother, 27:851-7.

Nightingale KK, Schukken YH, Nightingale CR, et al. 2004. Ecology and transmission of Listeria monocytogenes infecting ruminants and in the farm environment. Appl Environ Microbiol, 70:4458-67.

Navratilova P, Schlegelova J, Sustackova A, et al. 2004. Prevalence of Listeria monocytogenes in milk, meat and foodstuff of animal origin and the phenotype of antibiotic resistance of isolated strains. Vet Med-Czech, 49:243-52.

Schlech III WF. 2000. Food-borne listeriosis. Clin Infect Dis, 31:770-5.

Schuchat A, Swaminathan B, Broome CV. 1991. Epidemiology of human listeriosis. Clin Microbiol Rev, 4:169-83.
Soussy CJ. 2005. Edition de Janvier 2005. Comite de L'antibiogramme de La Société Française de Microbiologie. Communiqué 2005.

Van Schothorst M. 1994. Choice of sampling plan and criteria for Listeria monocytogenes, International Commission on Microbiological Specifications for Foods. Int J Food Microbiol, 22:89-96.

Wiggins GL, Albritton WL, Feeley JC. 1978. Antibiotic susceptibility of clinical isolates of Listeria monocytogenes. Antimicrob Agents Chemother, 13:854-60.

Winslow DL, Pankey GA. 1982. In vitro activities of trimethoprim and sulfamethoxazole against Listeria monocytogenes. Antimicrob Agents Chemother, 22:51-4.

Wong HC, Chao WL, Lee SJ. 1990. Incidence and characterization of Listeria monocytogenes in foods available in Taiwan. Appl Environ Microbiol, 56:3101-4.

Yucel N, Citak S, Önder M. 2005. Prevalence and antibiotic resistance of Listeria species in meat products in Ankara, Turkey. Food Microbiol, 22:241-5. 